\title{
Oil Pollution in the Southern Gulf of Mexico: Field and Laboratory Studies
}

\author{
Gerardo Gold-Bouchot ${ }^{1}$
}

Received: 17 December 2021 / Accepted: 17 December 2021 / Published online: 22 December 2021

(c) The Author(s), under exclusive licence to Springer Science+Business Media, LLC, part of Springer Nature 2021

There is relatively little information on pollution problems in the Southern Gulf of Mexico as compared to other regions of the world. After the Macondo well Deep-Water Horizon Blowout many studies were funded by the Gulf of Mexico Research Initiative (GOMRI) and other funding sources on concentrations, fate, and effects of hydrocarbons in the northern Gulf of Mexico (GoM). Similar efforts by Mexico were funded, first through a series of three cruises per year for three years, and smaller projects studying coastal lagoons, sea grass beds, pollutants in sea turtle hatchlings, amongst others, and later through a major funding effort by the joint Department of Energy - CONACyT Energy Research Fund. These two programs greatly improved what we know of the Southern GoM, and particularly about the deeper parts, and the northern portion of the Mexican GoM. This special issue of BECT includes 16 papers, 15 from the two funding programs mentioned above, which give a broad perspective of pollution research in this area. Some papers discuss environmental distributions of metals, other papers discuss possible effects in the field, and some papers discuss laboratory experiments.

Cruz-Santiago et al. report genotoxicity in Giant Tadpoles (Rhinella marina) collected in industrial areas from the Coatzacoalcos River, where most of Mexico's petrochemical industry is located. Arceaga-Cabrera et al. report concentrations of dissolved cadmium and vanadium in surface water of the northern Yucatan Peninsula continental shelf. Cadmium concentrations were in the range for nonpolluted sites, whereas $25 \%$ of vanadium concentrations were in the polluted range. Dótor-Almazán et al. reported cadmium and vanadium concentrations in surface sediments collected from the Tamaulipas continental shelf. Results are like those previously reported for the same area and are not indicative of pollution. In another paper in this special

Gerardo Gold-Bouchot

ggold@tamu.edu

1 Texas A\&M University, College Station, TX, USA issue, Dótor-Almazán et al. report concentrations of trace metals in surface sediments collected from the northern Yucatan Peninsula continental shelf. Arceaga-Cabrera et al. report concentrations of dissolved cadmium and vanadium in surface water from the Perdido Folded Belt, along the United States of America-Mexico maritime border, finding concentrations similar to those of polluted areas. All the papers reporting metals conclude that circulation patterns, upwelling in the Yucatan Canal, and changes in river discharge along the Tamaulipas coast are some of the most important factors explaining spatial and temporal changes in metal concentrations.

Poot-Delgado et al. discuss spatial and temporal changes of harmful phytoplankton species along the coast of the state of Campeche. Blooms were observed at the beginning of the rainy season, with five species of bloom-forming species, and nine potentially toxic to human species found. Vidal-Martinez et al. used the metazoan parasites of the Dusky Flounder (Syacium papillosum), finding that functional groups gave similar results to analyses at species level, which saves time and money. García-Teh et al. used the metazoan parasite infracommunities of the Tomtate Grunt (Haemulon aureolineatus) as bioindicators of environmental health in the Yucatan Peninsula continental shelf. EkHuchim et al. used micronucleus and microcytes to assess genotoxicity in flounders in the Perdido Folded Belt and the Yucatan Peninsula, finding differences between the two locations, and associations with some pollutants, such as heavy metals and PAHs.

Couoh-Puga et al. exposed Sciaenops ocellatus to Mexican light oil for four and nine days, and studied the histopathology of the liver, kidneys, spleen, and gills. The highest prevalence of lesions was found in the liver and kidney, with strong associations to naphthalene, $\mathrm{Pb}, \mathrm{Cd}, \mathrm{Ni}$, and bile $\mathrm{PAH}$ metabolite concentrations. Améndola-Pimenta et al. studied differential gene expression in Limulus poliphemus larvae exposed to water-accommodated fraction (WAF) of Mexican light oil and chemically enhanced water accommodated 
fraction (CEWAF) with addition of Nokomis 3-F4. For $96 \mathrm{~h}$. Results showed an up-regulation of genes associated to detoxification processes (glutathione S-transferase, glutathione peroxidase), stress (heat shock protein), innate immunity (tumor necrosis factor receptor-associated factor 4traf4), cell death: apoptosis inhibitor 5 and DNA repairing. Cañizares-Martinez et al. exposed juvenile Sciaenops ocellatus to crude oil and found that fish exposed to crude oil exhibited hypomethylation of DNA, upregulation of CyP-1A and GsT, and down-regulation of GPX, CAT, aldh, VTG, and high concentrations of PAH metabolites in bile with respect to control fish.

Garcia-Bautista et al. optimized light crude oil degradation using the Response Surface Method, with degradation efficiencies for all hydrocarbon fractions higher than
$80 \%$. Uribe-Flores et al. studied the effect of the dispersant Nokomis 3-F4 on the bacterial degradation of a heavy crude oil, finding that the addition of dispersant increased degradation efficiency by $30.8 \%$.

Many thanks to Dr. Mace Barron, U. S. Environmental Protection Agency, for his assistance in facilitating the review and editorial processes. His help was instrumental to get this special issue finished.

Publisher's Note Springer Nature remains neutral with regard to jurisdictional claims in published maps and institutional affiliations. 